\title{
JUKMAS
}

Jurnal Untuk Masyarakat Sehat (JUKMAS)

e-ISSN : 2715-7687

Vol. 5, No. 1 April 2021

P-ISSN : 2715-8748

\section{Determinan Anemia Pada Ibu Hamil Di Puskesmas Campaka Kabupaten Purwakarta Januari-Juni 2018}

\author{
Wita Hefita Sari ${ }^{1}$, Herman Sudiman ${ }^{2}$, Darnialis Darwis $^{3}$
}

1. Program Pascasarjana, Program Studi Ilmu Kesehatan Masyarakat, Universitas Respati Indonesia Jl. Bambu Apus I No 3, Bambu Apus, Cipayung, Jakarta Timur 13890

whefitasari@gmail.com

2. Fakultas Ilmu Kesehatan Masyarakat, Universitas Respati Indonesia Jl. Bambu Apus I No.3, Bambu Apus, Cipayung, Jakarta Timur $13890 @$ urindo.ac.id

3. Falkustas IImu Kesehatan, Universitas Respati Indonesia Jl. Swadaya I No.83, Bambu Apus, Cipayung RT.3/RW.1, Jakarta Timur 13890 @ urindo.ac.id

\begin{abstract}
Abstrak
Meningkatnya ibu hamil yang mengalami masalah gizi khususnya gizi kurang seperti Kurang Energi Kronik (KEK) dan Anemia menurut Riset Kesehatan Dasar, 2013 diketahui bahwa prevalensi anemia pada ibu hamil di Indonesia sebesar 37, 1\%. Pemberian tablet Fe di Indonesia pada tahun 2012 sebesar $85 \%$. Prensentase ini mengalami peningkatan dibandingkan pada tahun 2011 yang sebesar $83,3 \%$. Penelitian ini bertujuan untuk mengetahui determinan yang mempengaruhi anemia pada ibu hamil di Puskesmas Campaka Kabupaten Purwakarta Provinsi Jawa Barat Periode Januari-Juni Tahun 2018. Penelitian ini menggunakan desain studi Case Control. Populasi yang berjumlah 41 orang. Hasil penelitian menunjukan ada pengaruh yang signifikan terhadap anemia pada ibu hamil antara pekerjaan ibu, paritas, usia kehamilan, jarak kehamilan, paritas, kepatuhan konsumsi tablet tambah darah dengan $p$-value $<0,05$, sebaliknya tidak ada pengaruh antara umur ibu, pendidikan, paritas. Faktor dominan terhadap anemia pada ibu hamil adalah pekerjaan $(0,050)$, usia kehamilan $(0,034)$, jarak kehamilan $(0,021)$.
\end{abstract}

Kata kunci: Umur, pendidikan, pekerjaan, dan paritas

\begin{abstract}
The increase in pregnant women who experience nutritional problems, especially malnutrition, such as Chronic Energy Deficiency (KEK) and Anemia according to Basic Health Research, 2013, revealed that the prevalence of anemia in pregnant women in Indonesia is $37,1 \%$. This percentage has increased compared to 2011 which amounted to 83.3\%. This study aims to determine the determinants that affect anemia in pregnant women in Campaka Health Center, Purwakarta Regency, West Java Province, January-June Period 2018. This study uses a Case Control study design. A population of 41 people. The results showed that there was a significant effect on anemia among pregnant women between maternal work, parity, gestational age, gestational distance, parity, compliance with consumption of tablets added to blood with a p-value $<0.05$, on the contrary there is no influence between maternal age, education, parity. The dominant factor for anemia in pregnant women is work (0.050), gestational age (0.034), gestational distance (0.021).
\end{abstract}

http://ejournal.urindo.ac.id/index.php/jukmas

Article History :

Submitted 22 Januari 2021, Accepted 28 April 2021, Published 30 April 2021 
Keywords : occupation, gestational age, distance of pregnancy, parity, consumption of blood added tablet, anaemia of pregnanct women.

\section{PENDAHULUAN}

Masalah gizi akan meningkatkan resiko kesakitan dan kematian bayi. Seorang ibu hamil akan melahirkan bayi yang sehat bila tingkat kesehatan dan gizinya berada pada kondisi yang baik. Namun sampai saat ini masih banyak ibu hamil yang mengalami masalah gizi khususnya gizi kurang seperti Kurang Energi Kronik (KEK) dan Anemia.

Anemia pada kehamilan ialah kondisi ibu dengan kadar hemoglobin di bawah 11 gr\% pada trimester 1 dan 3 atau kadar kurang dari 10,5 gr\% pada trimester 2 . Nilai batas tersebut dan perbedaannya dengan kondisi wanita tidak hamil terjadi karena hemodilusi terutama pada trimester 2 (Sarwono, 2012). Menurut WHO (2008), menggambarkan secara global prevalensi anemia pada ibu hamil di seluruh dunia adalah sebesar $41,8 \%$. Prevalensi anemia pada ibu hamil diperkirakan di Asia sebesar 48,2 \%, Afrika 57,1, Amerika 24,1 \%, dan Eropa 25,1\%.

Berdasarkan hasil Riset Kesehatan Dasar (Riskesdas) tahun 2013, prevalensi anemia pada ibu hamil di Indonesia sebesar 37, 1\%. Pemberian tablet Fe di Indonesia pada tahun 2012 sebesar 85\%. Prensentase ini mengalami peningkatan dibandingkan pada tahun 2011 yang sebesar 83,3\%.

Jumlah kunjungan ibu hamil pada tahun 2015 sebanyak 513 orang, sedangkan ibu hamil yang mengalami anemia sebanyak 6 orang $(1,17 \%)$ dan kunjungan ibu hamil tahun 2016 sebanyak 686 orang dengan jumlah ibu hamil yang mengalami anemia sebanyak 14 orang $(2,04 \%)$, kunjungan ibu hamil pada tahun 2017 sebanyak 468 orang dan ibu hamil yang mengalami anemia sebanyak 51 orang $(10,89 \%)$ (Data rekam medis Puskesmas Campaka Purwakarta, 2017).

\section{METODE}

Desain penelitian yang digunakan dalam penelitian ini adalah Case Control dengan sample kasus dengan populasi dalam penelitian ini adalah seluruh ibu hamil dengan anemia yang berkunjung di Puskesmas Campaka Purwakarta Periode Januari - Juni 2018 yang berjumlah 41 orang dengan
Sumber data yang diambil dalam penelitian ini adalah data primer dan sekunder. Data rekam medik berisi ibu hamil dengan anemia di Puskesmas Campaka Kabupaten Purwakarta Periode Januari-Juni 2018. Data primer dari variabel independen dengan membuat quesioner responden tentang kepatuhan konsumsi tambah darah dan budaya pantang makan. Data rekam medik yang berisi umur, pendidikan, pekerjaan, paritas, usia kehamilan, jarak kehamilan dan data primer kepatuhan konsumsi tablet tambah darah, budaya pantang makan. Pengukuran variabel independen menggunakan skala nominal, dimana pengukurannya dibagi menjadi 9 kategori. Dimana pengukuran Anemia pada ibu hamil $\mathrm{Hb} 7-8 \mathrm{gr} \%=$ Anemia Sedang dengan kategori 0 dan $\mathrm{Hb} 9-10 \mathrm{gr} \%$ $=$ Anemia Ringan dengan kategori 1 , umur yang berisiko $=<20$ dan $>35$ tahun dengan kategori 0 dan tidak beresiko $=20-35$ tahun dengan kategori 1 , pendidikan rendah = tidak sekolah, SD,SMP dengan ketegori 0 dan pendidikan tinggi $=$ SMK dan perguruan Tinggi dengan ketegori 1 , pekerjaan karyawan dengan kategori 0 dan pekerjaan ibu rumah tangga dengan kategori 1, Paritas multipara dengan kategori 0 dan paritas primipara dengan kategori 1, usia kehamilan trimester 2 (13-28 minggu) (kunjungan II) dengan kategori 0 dan trimester 3 (29-40 minggu) (kunjungan III dan IV) dengan kategori 1, Jarak kehamilan berisiko $<36->48$ bulan dengan kategori 0 dan tidak berisiko $36-48$ bulan dengan kategori 1 , kepatuhan konsumsi tablet tambah darah tidak teratur (diterima 30 tablet=konsumsi<>1 $x$ sehari dengan kategori 0 dan teratur diterima 30 tablet $=1$ bulan;konsumsi $1 \mathrm{x}$ sehari dengan kategori 1 , budaya pantan makan ada pantangan dengan kategori 0 dan tidak ada pantangan dengan kategori 1 . Metode analisis data yang digunakan meliputi analisis univariat, analisis bivariat dengan ChiSquare dan analisis multivariate dengan uji statistic regresi logistic. Waktu penelitian dilakukan pada Juni 2018. 


\begin{tabular}{|c|c|c|}
\hline Umur ibu & $\mathbf{n}$ & $\%$ \\
\hline$<20$ Tahun & 13 & 5,9 \\
\hline $20-35$ Tahun & 40 & 48,8 \\
\hline$>35$ Tahun & 29 & 35,4 \\
\hline Pendidikan ibu & $\mathbf{n}$ & $\%$ \\
\hline Tidak sekolah & 12 & 14,6 \\
\hline SD & 15 & 18,3 \\
\hline SMP & 10 & 12,2 \\
\hline SMA & 36 & 43,9 \\
\hline Perguruan Tinggi & 9 & 11 \\
\hline Pekerjaan ibu & $\mathbf{n}$ & $\%$ \\
\hline Karyawan & 36 & 43,9 \\
\hline Ibu rumah tangga & 46 & 56,1 \\
\hline Paritas & $\mathbf{n}$ & $\%$ \\
\hline Primipara & 34 & 41,5 \\
\hline Multipara & 48 & 58,5 \\
\hline Usia kehamilan & $\mathbf{n}$ & $\%$ \\
\hline Trimester II & 38 & 46,3 \\
\hline Trimester III & 44 & 53,7 \\
\hline Jarak kehamilan & $\mathbf{n}$ & $\%$ \\
\hline Tidak ada & 33 & 40,2 \\
\hline$<36$ minggu & 17 & 20,7 \\
\hline 36-48 minggu & 16 & 19,5 \\
\hline$>48$ minggu & 16 & 19,5 \\
\hline $\begin{array}{c}\text { Kepatuhan } \\
\text { konsumsi TTD }\end{array}$ & $\mathbf{n}$ & $\%$ \\
\hline Tidak teratur & 45 & 54,9 \\
\hline Teratur & 37 & 45,1 \\
\hline $\begin{array}{c}\text { Budaya pentang } \\
\text { makan }\end{array}$ & $\mathrm{n}$ & $\%$ \\
\hline Tidak ada & 62 & 75,6 \\
\hline Daging-dagingan & 8 & 9,8 \\
\hline Sayur-sayuran & 6 & 7,3 \\
\hline Minuman berwarna & 6 & 7,3 \\
\hline Jumlah & 82 & 100 \\
\hline
\end{tabular}

Tabel 1 Distribusi Frekuensi Variabel Independen

Berdasarkan Tabel 1 diketahui bahwa sebagian besar umur ibu yang tidak berisiko 20-35 tahun $(48,8)$, pendidikan SMA $(43,9 \%)$, pekerjaan ibu sebagai ibu rumah tangga $(56,1 \%)$, paritas multipara $(58,5)$, usia kehamilan (53,7\%), jarak kehamilan Trimester I (40,2\%), kepatuhan konsumsi TTD tidak teratur $(54,9 \%)$ dan tidak ada budaya pantang makan $(75,6)$.

Tabel 2 Hubungan Anemia pada ibu hamil dengan variabel independen

Umur ibu

\begin{tabular}{|c|c|c|c|c|c|c|}
\hline & \multicolumn{2}{|c|}{ Kasus } & \multicolumn{2}{|c|}{ Kontrol } & & \\
\hline & $n$ & $\%$ & $\mathrm{n}$ & $\%$ & & \\
\hline$<20-35>$ & 23 & 56,1 & 19 & 46,3 & 0,507 & $1,480 \quad 0,6-3,5$ \\
\hline $\begin{array}{l}\text { 0/20-35 } \\
\text { Tahun }\end{array}$ & 18 & 43,9 & 22 & 53,7 & & \\
\hline $\begin{array}{l}\text { Pendidikan } \\
\text { ibu }\end{array}$ & $n$ & $\%$ & $n$ & $\%$ & p-value & OR $(95 \% \mathrm{Cl})$ \\
\hline $\begin{array}{l}\text { Pendidikan } \\
\text { Rendah } \\
\text { (TS,SD,SMP) }\end{array}$ & 18 & 43,9 & 19 & 46,3 & 1,000 & $0,9060,3-2,1$ \\
\hline $\begin{array}{l}\text { Pendidikan } \\
\text { Tinggi(SMA, } \\
\text { PT) }\end{array}$ & 23 & 56,1 & 22 & 53,7 & & \\
\hline $\begin{array}{l}\text { Pekerjaan } \\
\text { ibu }\end{array}$ & $n$ & $\%$ & $n$ & $\%$ & P-velue & OR \\
\hline Karyawan & 12 & 29,3 & 24 & 58,5 & 0,014 & $0,2930,1-0,7$ \\
\hline IRT & 29 & 70,7 & 17 & 41,5 & & \\
\hline Paritas & $n$ & $\%$ & $n$ & $\%$ & p-value & OR (95\%ci) \\
\hline Primpara & 10 & 24,4 & 24 & 58,5 & 0,004 & $4,376 \quad 1,7-11,2$ \\
\hline Multipara & 31 & 75,6 & 17 & 41,5 & & \\
\hline $\begin{array}{l}\text { Usia } \\
\text { kehamilan }\end{array}$ & $n$ & $\%$ & $n$ & $\%$ & p-value & OR (95\%ci) \\
\hline Trimester II & 24 & 58,5 & 14 & 34,1 & 0,046 & $2,723 \quad 1,1-6,6$ \\
\hline Trimester III & 17 & 41,5 & 27 & 27 & 65,9 & \\
\hline $\begin{array}{l}\text { Jarak } \\
\text { kehamilan }\end{array}$ & $n$ & $\%$ & $n$ & $\%$ & p-value & OR (95\%ci) \\
\hline$<36->48$ & 24 & 58,5 & 9 & 22,0 & 0,002 & $5,0201,9-13,1$ \\
\hline $0 / 36-48$ & 17 & 41,5 & 32 & 78,0 & & \\
\hline $\begin{array}{l}\text { Konsumsi } \\
\text { TTD }\end{array}$ & $n$ & $\%$ & $n$ & $\%$ & P-value & OR(95\%Cl) \\
\hline $\begin{array}{l}\text { Tidak } \\
\text { teratur }\end{array}$ & 30 & 73,2 & 15 & 36,6 & 0,002 & $4,727 \quad 1,8-12,0$ \\
\hline Teratur & 11 & 26,8 & 26 & 63,4 & & \\
\hline $\begin{array}{l}\text { Budaya } \\
\text { pantang } \\
\text { makan }\end{array}$ & $n$ & $\%$ & $n$ & $\%$ & p-value & OR $(95 \% \mathrm{Cl})$ \\
\hline $\begin{array}{l}\text { Ada } \\
\text { pantangan }\end{array}$ & 12 & 29,3 & 8 & 19,5 & 0,440 & $1,707 \quad 0,6-4,7$ \\
\hline Tidak ada & 29 & 70,7 & 33 & 80,5 & & \\
\hline Total & 41 & 100 & 41 & 100 & & \\
\hline
\end{tabular}

Hubungan antara umur ibu dengan anemia pada ibu hamil

OR

(95\%Cl) 
Berdasarkan hasil penelitian bahwa bahwa ibu hamil dengan anemia di kelompok kasus ditemukan 23 orang $(56,1 \%)$ dengan umur berisiko sedangkan pada kelompok kontrol sebanyak19 (46,3\%) . Hasil uji statistik menggunakan $\mathrm{Chi}$ Square diperoleh $P$ value $=0,507$ berarti secara statistik tidak berpengaruh terhadap anemia pada ibu hamil. Hasil analisis diperoleh nilai $O R=1,480$ artinya responden yang mempunyai umur berisiko memiliki faktor risiko satu kali terjadinya anemia dibandingkan dengan responden yang berumur tidak resiko.

Penelitian ini tidak sejalan berbanding terbalik dengan penelitian Willy Astriana, 2017 dengan penelitian 118 responden yang mengalami kejadian anemia dengan usia beresiko yaitu 94 responden $(47,2 \%)$ lebih besar dibandingkan responden dengan usia tidak bersiko yaitu 24 responden (30,8\%). Hasil uji statistik Chi-Square di dapatkan $p$ value 0,018 ( $p<0,05)$. Ini menunjukkan bahwa terdapat hubungan yang bermakna antara umur dengan kejadian anemia pada ibu hamil. Berdasarkan hasil analisis maka hipotesa yang diajukan diterima, yaitu terdapat hubungan yang bermakna antara umur dengan kejadian anemia pada ibu hamil.

Penelitian ini berbanding terbalik dengan literatur Amirudin, 2014, menyatakan bahwa.hubungan dengan anemia bahwa pada umur $<20$ tahun dapat menyebabkan anemia karena pada umur tersebut perkembangan biologis dalam hal ini alat reproduksi belum optimal. Pada umur belia tersebut, psikologis yang belum matang juga menyebakan wanita hamil mudah mengalami guncangan mental yang mengakibatkan kurangnya perhatian terhadap pemenuhan kebutuhan zat-zat gizi selain kehamilannya. Selain kehamilan diabawah umur 20 tahun, kehamilan dengan umur diatas 35 tahun juga merupakan kehamilan berisiko tinggi. Wanita yang hamil dalam umur yang terlalu tua yaitu $>35$ tahun pun akan rentan terhadap anemia. Hal ini berkaitan dengan penurunan daya tahan tubuh sehingga mudah terkena berbagai infeksi selama kehamilan

\section{Hubungan antara pendidikan ibu dengan anemia pada ibu hamil}

Hasil penelitian saya diketahui bahwa ibu hamil dengan anemia di kelompok kasus ditemukan 18 orang $(43,9 \%)$ dengan pendidikan rendah sedangkan pada kelompok kontrol sebanyak 19 orang $(46,3 \%)$. Hasil uji statistik menggunakan Chi Square diperoleh $P$-value $=1,000$ berarti secara statistik tidak berpengaruh terhadap anemia pada ibu hamil. Hasil analisis diperoleh nilai $\mathrm{OR}=0,906$ artinya responden yang mempunyai pendidikan rendah memiliki faktor protektif terjadinya anemia dibandingkan dengan responden yang berpendidikan tinggi.

Penelitian ini sejalan dengan penelitian Widya Yuliarti, 2017 bahwa 49 responden ibu hamil dengan pendidikan tinggi 22 responden $(56,4 \%)$, dengan $p$ value 0,176 maka diartikan bahwa tidak ada hubungan yang signifikan antara pendidikan ibu dengan anemia pada ibu hamil.

Tidak sejalan dengan literatur Arisman, 2011, hal 152, menyatakan bahwa pendidikan adalah proses perubahan perilaku menuju kedewasaan dan penyempurnaan hidup. Biasanya seorang ibu khususnya ibu hamil yang berpendidikan tinggi dapat menyeimbangkan pola konsumsi dan asupan zat gizi yang dibutuhkan. Agar mengerti wanita hamil harus diberi pendidikan yang tepat misalnya bayi yang mungkin terjadi akibat anemia, dan harus pula diyakinkan bahwa salah satu penyebab anemia adalah defisiensi zat besi.

\section{Hubungan antara pekerjaan dengan anemia pada ibu hamil}

Hasil penelitian didapatkan uji statistic ChiSquare diperoleh $p$-value $<0,05$ adalah pekerjaan Hasil penelitian diketahui bahwa bahwa ibu hamil dengan anemia di kelompok kasus ditemukan 12 orang $(29,3 \%)$ dengan pekerjaan ibu sebagai karyawan sedangkan pada kelompok kontrol sebanyak 24 orang (58,5\%) .Hasil uji statistik menggunakan Chi Square diperoleh $P$-value $=0,014$ berarti secara statistik berpengaruh terhadap anemia pada ibu hamil. Hasil analisis diperoleh nilai 
$\mathrm{OR}=0,293$ artinya responden yang mempunyai bekerja sebagai karyawan memiliki faktor protektif terjadinya anemia dibandingkan dengan responden yang bekerja sebagai ibu rumah tangga.

Penelitian ini tidak sejalan dengan penelitian I.G.B. Ngurah Rai dkk,2016 bahwa hasil analisis hubungan antara kadar hemoglobin dengan status pekerjaan responden, hasil penelitian ini sesuai dengan penelitian yang dilakukan RD Aisyah bahwa 60,9\% responden yang mengalami anemia memiliki status pekerjaan bekerja dan $74,2 \%$ responden yang mengalami anemia dengan status pekerjaan tidak bekerja. Dari hasil analisis di dapatkan nilai $p=0,201$ sehingga tidak terdapat hubungan yang bermakna antara kadar hb dengan pekerjaan.18 Dari data diatas dapat disimpulkan bahwa terdapat hubungan bermakna antara teori dan hasil penelitian tentang pekerjaan ibu hamil dengan anemia.

Sejalan dengan literatur Islamiyati, 2005 menyatakan bahwa salah satu penyebabkan tidak langsung anemia gizi pada ibu hamil adalah status pekerjaan ibu karena status pekerjaan biasaannya berkaitan erat dengan pendidikan dan pendapatan seseorang. Ibu hamil yang tidak bekerja lebih cenderung untuk mengalami anemia dibandingkan dengan ibu yang bekerja hal ini kemungkinan disebabkan karena ibu yang bekerja biasanya berkaitan erat dengan pendidikan dan pendapatan seseorang. Ibu hamil yang tidak bekerja lebih cenderung untuk mengalami anemia dibandingkan dengan ibu yang bekerja hal ini kemungkinan disebabkan karena ibu yang bekerja biasanya mempunyai pendapatan yang cukup mengandung zat besi.

\section{Hubungan antara paritas dengan anemia pada ibu hamil}

Hasil penelitian saya mendapatkan hasil bahwa ibu hamil dengan anemia di kelompok kasus ditemukan 10 orang $(24,4 \%)$ dengan paritas primipara sedangkan pada kelompok kontrol sebanyak 24 orang $(58,5 \%)$. Hasil uji statistik menggunakan Chi Square diperoleh $P$ value $=0,004$ berarti secara statistik berpengaruh terhadap anemia pada ibu hamil. Hasil analisis diperoleh nilai $\mathrm{OR}=4,376$ artinya responden yang mempunyai paritas primipara memiliki faktor resiko terjadinya anemia dibandingkan dengan responden yang paritas multipara.

Penelitian ini tidak sejalan dengan penelitian Willy Astria, 2017 yang berjudul kejadian anemia pada ibu hamil ditinjau dari paritas dan usia. Hasil uji statistik Chi-Square di dapatkan $p$ value 0,023 ( $p<0,05)$. Ini menunjukkan menunjukkan ada hubungan yang bermakna antara paritas dengan kejadian anemia pada ibu hamil. Maka hipotesa yang menyatakan bahwa ada hubungan yang bermakna antara paritas dengan kejadian anemia pada ibu hamil terbukti.

Sejalan dengan literatur Arisman, 2011, hal 150, menyatakan bahwa paritas adalah jumlah kehamilan yang menghasilkan janin mampu hidup diluar rahim. Paritas $>3$ merupakan faktor terjadinya anemia. Hal ini disebabkan karena terlalu sering hamil dapat menguras cadangan zat gizi tubuh ibu.

\section{Hubungan antara usia kehamilan dengan anemia pada ibu hamil}

Hasil penelitian saya menyatakan bahwa ibu hamil dengan anemia di kelompok kasus ditemukan 24 orang $(58,5 \%)$ dengan usia kehamilan trimester II sedangkan pada kelompok kontrol sebanyak 14 orang $(34,1 \%)$. Hasil uji statistik menggunakan Chi Square diperoleh $P$-value $=0,046$ berarti secara statistik berpengaruh terhadap anemia pada ibu hamil. Hasil analisis diperoleh nilai $\mathrm{OR}=2,723$ artinya responden yang mempunyai usia kehamilan primipara memiliki faktor protektif terjadinya anemia dibandingkan dengan responden usia kehamilan trimester III.

Penelitian dari sejalan dengan penelitian dari literatur Pusdiknakes, 2003 menyatakan bahwa masa kehamilan dibagi dalam 3 (tiga) tahap umur kehamilan yaitu: trimester I (pertama), II (Kedua), dan III (ketiga). Trimester I (pertama ) yaitu saat kehamilan berumur 1-3 bulan (0-12 minggu) adalah masa penyesuaian ibu terhadap awal kehamilannya. 
Pertumbuhan janin masih berlangsung lambat, sehingga kebutuhan zat gizi masih relative kecil. Pada tahap ini terjadi penurunan nafsu makan ibu sebagai akibat pengaruh hormonal sehingga pertambahan berat badan ibu hamil diperkiraka kurang lebih $1 \mathrm{~kg}$.

\section{Hubungan antara jarak kehamilan dengan anemia pada ibu hamil}

Hasil penelitian saya dikatahui bahwa ibu hamil dengan anemia di kelompok kasus ditemukan 24 orang $(58,5 \%)$ dengan jarak kehamilan yang berisiko sedangkan pada kelompok kontrol sebanyak 9 orang (22,0\%) . Hasil uji statistik menggunakan Chi Square diperoleh $P$-value $=0,002$ berarti secara statistik berpengaruh terhadap anemia pada ibu hamil. Hasil analisis diperoleh nilai $\mathrm{OR}=5,020$ artinya responden yang mempunyai jarak kehamilan berisiko memiliki faktor protektif terjadinya anemia dibandingkan dengan responden jarak kehamilan tidak berisiko.

Penelitian ini sejalan dengan penelitian Devi Anggra Ningrum, 2014 menyatakan bahwa hasil penelitian menunjukkan bahwa setengahnya dari responden memiliki jarak kehamilan < 2 tahun yaitu 15 responden (50,0\%), sedangkan kejadian anemia 15 orang mengalami Anemia, mereka yang memiliki jarak kehamilan $<2$ tahun hampir setengahnya mengalami Anemia ringan. Setelah dilakukan uji Chi Square menunjukkan nilai $P$ value sebesar 0,004 maka nilai Pvalue < 0,05 dan diperoleh Xhitung 10,971. Jadi HO ditolak artinya ada Hubungan antara jarak kehamilan dengan kejadian anemia pada kehamilan.

\section{Hubungan antara kepatuhan konsumsi tablet tambah darah}

Dari hasil analisis tabel 5.23 diatas terlihat bahwa ibu hamil dengan anemia di kelompok kasus ditemukan 30 orang $(73,2 \%)$ dengan konsumsi tablet tambah darah tidak teratur sedangkan pada kelompok kontrol sebanyak 15 orang $(36,6 \%)$. Hasil uji statistik menggunakan Chi Square diperoleh $P$ value $=0,002$ berarti secara statistik berpengaruh terhadap anemia pada ibu hamil. Hasil analisis diperoleh nilai $\mathrm{OR}=4,727$ artinya responden yang mempunyai kepatuhan konsumsi tablet tambah tidak teratur memiliki faktor risiko terjadinya anemia dibandingkan dengan responden kepatuhan konsumsi tablet tambah darah teratur.

Ditemukannya teori yang mendukung, menurut teori Wiknjosastro, dkk (2005) keperluan akan zat besi pada kehamilan akan bertambah terutama pada trimester akhir, pada proses pematangan sel darah merah zat besi diambil dari transferin plasma yaitu cadangan besi dalam serum. Apabila cadangan plasma tidak cukup maka akan mudah terjadi anemia. Hal yang sama ditemukan oleh Buana (2004), ibu hamil yang mendapatkan / mengkonsumsi tablet besi $<30$ tablet/bulan mempunyai peluang 2,286 kali untuk menderita anemia dibanding ibu hamil yang mengkonsumsi tablet besi $>30$ tablet/bulan.

\section{Hubungan antara budaya pantang makan}

Penelitian saya mendapatkan hasil bahwa bahwa ibu hamil dengan anemia di kelompok kasus ditemukan 12 orang $(73,2 \%)$ dengan tidak ada pantangan makanan sedangkan pada kelompok kontrol sebanyak 8 orang $(19,5 \%)$. Hasil uji statistik menggunakan Chi Square diperoleh $P$-value $=0,440$ berarti secara statistik tidak berpengaruh terhadap anemia pada ibu hamil. Hasil analisis diperoleh nilai $\mathrm{OR}=1,707$ artinya responden yang mempunyai budaya pantang makan faktor protektif terjadinya anemia dibandingkan dengan responden tidak ada pantang makan.

Penelitian ini sejalan dengan penelitian Fita Khasanah, 2017 menyatakan bahwa segaian besar responden mempunyai tingkat kepercayaan terhadap mitos tentang makanan dalam kehamilan dalam ketegori tinggi sebanya 22 responden (41,5\%). Hasil uji statistik menggunakan chi square di peroleh nilai $p$ value $=0,008$. Sehingga dapat disimpulkan bahwa $p<0,05$ hal ini menunjukan bahwa ada hubungan tingkat kepercayaan terhadap mitos tentang makanan dalam kehamilan dengan ukuran lingkar lengan atas ibu hamil. 
Berdasarkan literatur Syafruddin, 2016 menyatakan bahwa pengaruh social budaya sangat jelas terlihat pada ibu hamil dari keluarga yang menyambut masa-masa kehamilan. Upacara-upacara yang diselenggarakan mulai dari kehamilan 3 bulan, 7 bulan, masa melahirkan dan masa nifas sangat beragam menurut adat istiadat daerah masing-masing. Kebiasaan berpantang makanan yang terjadi di kalangan ibu hamil untuk tidak mengkonsumsi sejumlah makanan yang dapat menambahkan jumlah anemia pada ibu hamil.

Tabel 3 Analisis Bivariat dengan uji regresi logistik sederhana antara variabel independen dengan dependen

\begin{tabular}{lcc}
\hline \multicolumn{1}{c}{ Variabel } & $\begin{array}{c}\boldsymbol{p} \text { - } \\
\text { value }\end{array}$ & Keterangan \\
\hline Umur & 0,376 & Bukan Kandidat \\
\hline Pendidikan & 0,824 & Bukan Kandidat \\
\hline Pekerjaan & 0,007 & Kandidat \\
\hline Paritas & 0,001 & Kandidat \\
\hline Usia Kehamilan & 0,026 & Kandidat \\
\hline $\begin{array}{l}\text { Jarak Kehamilan } \\
\text { Kepatuhan Konsumsi }\end{array}$ & 0,001 & Kandidat \\
TTD & 0,001 & Kandidat
\end{tabular}

\begin{tabular}{lcccc}
\cline { 2 - 5 } & & & Lower & Upper \\
\hline Paritas & 0,249 & 1,961 & 0,624 & 6,165 \\
Pekerjaan & 0,050 & 3,081 & 0,998 & 9,517 \\
Usia Kehamilan & 0,034 & 0,308 & 0,103 & 0,917 \\
Jarak Kehamilan & 0,243 & 0,243 & 0,074 & 0,804 \\
$\begin{array}{l}\text { Kepatuhan } \\
\text { Konsumsi TTD }\end{array}$ & 0,135 & 0,432 & 0,144 & 1,300
\end{tabular}

Dari hasil analisis terlihat ada 2 variabel yang $p$-value nya $>0,05$ yaitu paritas dan kepatuhan konsumsi tablet tambah darah yang terbesar adalah paritas, sehingga pemodelan selanjutnya variabel paritas dikeluarkan dari model.

\begin{tabular}{lcccc}
\hline \multicolumn{1}{c}{ Variabel } & $\begin{array}{c}p- \\
\text { value }\end{array}$ & OR & \multicolumn{2}{c}{$95 \% \mathrm{Cl}$} \\
\cline { 4 - 5 } & & & Lower & Upper \\
\hline Pekerjaan & 0,050 & 3,081 & 0,998 & 9,517 \\
Usia kehamilan & 0,034 & 0,308 & 0,103 & 0,917 \\
Jarak kehamilan & 0,021 & 0,243 & 0,074 & 0,804 \\
Paritas & 0,249 & 1,961 & 0,624 & 6,165 \\
Kepatuhan konsumsi TTD & 0,135 & 0,432 & 0,144 & 1,300 \\
\hline
\end{tabular}

Tabel 5 Pemodelan Multivariat II (Perubahan nilai OR Setelah paritas dikeluarkan dari model)

\begin{tabular}{|c|c|c|c|c|c|}
\hline \multirow[t]{2}{*}{ Variabel } & \multirow{2}{*}{$\begin{array}{c}p- \\
\text { value }\end{array}$} & \multirow[t]{2}{*}{ OR } & \multicolumn{2}{|c|}{$95 \% \mathrm{Cl}$} & \multirow{2}{*}{$\begin{array}{c}\text { Perubah } \\
\text { an } \\
\text { (OR\%) }\end{array}$} \\
\hline & & & Lower & Upper & \\
\hline Pekerjaan & 0,031 & 3,389 & 1,122 & 10,239 & $-9,99$ \\
\hline Usia Kehamilan & 0,039 & 0,325 & 0,112 & 0,946 & $-5,51$ \\
\hline Jarak Kehamilan & 0,005 & 0,197 & 0,063 & 0,612 & 18,93 \\
\hline $\begin{array}{l}\text { Kepatuhan } \\
\text { Konsumsi TTD }\end{array}$ & 0,095 & 0,397 & 0,134 & 1,175 & 8,10 \\
\hline
\end{tabular}

Setelah variabel dikeluarkan usia kehamilan dari model. Kemudian lihat kembali perubahan OR $>10 \%$ pada variabel jarak kehamilan. Dari analisis perbandingan OR, ternyata perubahannya $>10 \%$ dan variabel paritas dimasukan lagi ke dalam model. Dengan demikian variabel yang $p$-value $>0,05$, 
variabel dikeluarkan yaitu kepatuhan konsumsi tablet tambah darah dikeluarkan dari model dan hasilnya:

Tabel.6 Pemodelan Multivariat III (Perubahan nilai OR Setelah kepatuhan konsumsi tablet tambah darah dikeluarkan dari model)

\begin{tabular}{lccccc}
\hline \multirow{2}{*}{$\begin{array}{c}\text { Variabel } \\
\text { value }\end{array}$} & & OR & \multicolumn{2}{c}{$95 \% \mathrm{Cl}$} & \multirow{2}{*}{$\begin{array}{l}\text { Peruba } \\
\text { han OR }\end{array}$} \\
\cline { 4 - 5 } & & & Lower & Upper & \\
\hline Pekerjaan & 0,016 & 3,834 & 1,282 & 11,467 & $-13,13$ \\
Usia hamil & 0,022 & 0,285 & 0,097 & 0,837 & 12,30 \\
Jarak hamil & 0,008 & 0,202 & 0,062 & 0,660 & $-2,5$ \\
Paritas & 0,171 & 2,182 & 0,714 & 6,669 & $-11,26$
\end{tabular}

Hasil analisis multivariat dihasilkan bahwa ada dua variabel yang memiliki perubahan $\mathrm{OR}>10$ $\%$ yaitu variabel paritas, pekerjaan, usia kehamilan, maka variabel kepatuhan konsumsi tablet tambah darah dimasukan kembali kedalam pemodalan multivariat

Tabel 7 Pemodelan Multivariat IV(Perubahan nilai OR Setelah kepatuhan konsumsi tablet tambah darah di masukan kembali di model)

Hasil analisis multivariat dihasilkan bahwa ada 5 variabel yang berhubungan signifikan dengan anemia pada ibu hamil yaitu variabel yang paling dominan mempengaruhi anemia pada ibu hamil yaitu variabel paritas, pekerjaan, usia kehamilan, jarak kehamilan, kepatuhan konsumsi tablet tambah darah. Variabel Paritas memiliki $p$ value $>0,05$ dan belum pernah di keluarkan dari pemodelan, variabel pekerjaan dengan (OR 1,961) sebagai faktor dominan terhadap kejadian anemia pada ibu hamil dengan OR $>1$ merupakan faktor risiko terhadap anemia pada ibu hamil, usia kehamilan (OR 0,308) sebagai faktor dominan dalam kejadian anemia pada ibu hamil dengan $O R$ artinya apabila $O R<1$ merupakan faktor protektif tetapi tidak berisiko anemia pada ibu hamil, jarak kehamilan $(O R 0,243)$ sebagai faktor dominan dalam kejadian anemia pada ibu hamil dengan $\mathrm{OR}<1$ merupakan faktor protektif tetapi tidak berisiko anemia pada ibu hamil.

Tabel. 8 Perubahan nilai OR Setelah kepatuhan konsumsi tablet tambah darah dimasukan di model

\begin{tabular}{lcccc}
\hline \multicolumn{1}{c}{ Variabel } & $p$-value & OR & \multicolumn{2}{c}{$95 \% \mathrm{Cl}$} \\
\cline { 4 - 5 } & & & Lower & Upper \\
\hline Pekerjaan & 0,050 & 3,081 & 0,998 & 9,517 \\
Usia hamil & 0,034 & 0,308 & 0,103 & 0,917 \\
Jarak hami & 0,021 & 0,243 & 0,074 & 0,804 \\
Paritas & 0,249 & 1,961 & 0,624 & 6,165 \\
$\begin{array}{l}\text { Kepatuhan } \\
\text { konsumsi TTD }\end{array}$ & 0,135 & 0,432 & 0,144 & 1,300 \\
\hline
\end{tabular}

Hasil analisis multivariat dihasilkan bahwa ada 3 variabel yang berhubungan signifikan dengan anemia pada ibu hamil yaitu variabel yang dominan mempengaruhi anemia pada ibu hamil yaitu variabel pekerjaan, usia kehamilan, jarak kehamilan. Variabel Paritas memiliki $p$ value $>0,05$ dan belum pernah di keluarkan dari pemodelan. Variabel pekerjaan dengan (OR 3,081) sebagai faktor dominan terhadap kejadian anemia pada ibu hamil dengan OR $>1$ merupakan faktor risiko terhadap anemia pada ibu hamil, usia kehamilan $(O R 0,308)$ sebagai faktor dominan dalam kejadian anemia pada ibu hamil. Apabila $O R<1$ merupakan faktor protektif tetapi tidak berisiko anemia pada ibu hamil, jarak kehamilan $(O R \quad 0,243)$ sebagai faktor dominan dalam kejadian anemia pada ibu hamil dengan $\mathrm{OR}<1$ merupakan faktor protektif tetapi tidak berisiko anemia pada ibu hamil.

\section{KESIMPULAN}

Anemia pada ibu hamil berjumlah 41 orang. Diketahui bahwa frekuensi terbanyak yang mengalami anemia ringan dengan jumlah 30 orang $(36,6 \%)$. Berdasarkan umur ibu hamil dengan anemia sebagian besar pada umur 2035 tahun dengan jumlah 40 orang $(48,8 \%)$, pendidikan ibu terbanyak adalah SMA sebanyak 36 orang (43,9\%), pekerjaan terbanyak ibu rumah tangga 46 orang $(56,1 \%)$, paritas terbanyak multipara yaitu 48 orang $(41,5 \%)$, usia kehamilan terbanyak pada trimester II sebagian besar 44 orang $(53,7 \%)$, jarak kehamilan belum pernah melahirkan sebelumnya sebagian kecil 33 orang $(40,2 \%)$, kepatuhan konsumsi tablet tambah darah terbanyak konsumsi tidak teratur 45 orang $(54,9 \%)$, budaya pantang makan tidak ada pantangan terbanyak 62 orang $(75,6 \%)$ 
Hasil analisis bivariat yang menjadi kandidat determinan anemia pada ibu hamil adalah variabel paritas dengan $p$ value 0,001 , pekerjaan dengan $p$ value 0,007 , usia kehamilan dengan $p$ value 0,026 , jarak kehamilan dengan $\mathrm{p}$-value 0,001 , kepatuhan konsumsi tablet tambah darah $p$ value 0,001 dan Dari hasil tersebut yang paling dominan adalah pekerjaan dengan $p$ value 0,050 , usia kehamilan dengan $p$ value 0,034 , dan jarak kehamilan dengan $p$ value 0,243 , yang berarti ada pengaruh yang signifikan terhadap anemia pada ibu hamil.

\section{DAFTAR PUSTAKA}

[1] Almatsier, S. (2002). Prinsip Dasar Ilmu Gizi. Jakarta: PT Gramedia.

[2] Anggraini, D. U. (2016). Hubungan Kejadian Anemi Pada Ibu Hamil Dengan Kejadian BBLR di RSUD Ambarawa Kabupaten Semarang. Jawa Tengah: Artikel Universitas Ngudi Waluyo.

[3] Ani, S. (2013). Anemia Defesiensi Besi. Penerbit Buku Kedokteran EGC: Jakarta.

[4] Arisman. (2011). Gizi Dalam Daur Kehidupan : Buku Ajar Ilmu Gizi. Jakarta: EGC.

[5] Aryanti Wardiah, d. (2013). Faktor-Faktor Yang Mempengaruhi Kejadian Anemia Pada Ibu Hamil Di Wilayah Kerja Puskesmas Sekampung Kabupaten Lampung Tahun 2013. Lampung: PSIK Univeritas Malayati.

[6] Astriana, W. (2017). Kejadian Anemia Pada Ibu Hamil Ditinjau Dari Paritas Dan Kesehatan . Sumatera Selatan: Jurnal IImu Kesehatan Program Studi DIII Kebidanan STIKES AI-Ma'Arif Batubaja.

[7] Dameria M, T. (2011). Gambaran Kejadian Anemia Ibu Hamil Dan Faktor-Faktor Yang Berhubungan Di Wilayah Kerja Puskesmas Sei Apung Kab Asahan.
Sumatera Utara: Tesis Universitas Indonesia.

[8] Emma, S. W. (1999). Perencanaan Menu Anemia Gizi Besi. Jakarta: Trubus Agriwidya.

[9] Manuaba, I. (t.thn.). Ilmu Kebidanan Penyakit Kandungan Dan Keluarga Berencana Untuk Pendidikan Bidan. Jakarta: EGC.

[10] Musbikim, I. (2008). Panduan Ibu Hamil Dan Melahirkan. Yogyakarta: Mitra Pustaka.

[11] Ningrum, D. A. (2014). Hubungan Jarak Kehamilan Dengan Kejadian Anemia Pada Kehamilan Di BPS Ny. U Desa Sooko Kec Sooko. Kab Mojokerto . Jawa Timur: Karya Tulis IImiah.

[12] Norfai. (2015). Konsumsi Tablet Besi (Fe) Sebagai Determinan Kejadian Anemia Pada Ibu Hamil Di Wilayah Kerja Puskesmas Alalak Tengah Kota Banjarmasin. Jakarta: Tesis Universitas Respati Indonesia.

[13] Notoatmodjo, S. (2013). Pendidikan Dan perilaku Kesehatan. Jakarta: Rineka Media.

[14] Noverstitim, E. (2012). Faktor-faktor Yang Berhubungan Dengan Kejadian Anemia Pada Ibu Hamil Trimester III di Wilayah Kerja Puskesmas Air Dingin Kota Padang tahun 2012. Sumatera Barat: STIKES Peringsewu Lampung.

[15] Nurhidayati, R. D. (2013). Analisis Faktor Penyebab Terjadinya Anemia Pada Ibu Hamil Di Wilayah Kerja Psukesmas Tawangsari Kab Sukoharjo. Jawa Tengah: Skripsi.

[16] Nurjanah, D. (2012). Hubungan Antara Paritas Dan Umur Dengan Anemia Pada 
Ibu Hamil Trimester III Tahun 2012. Semarang: Universitas Muhammadiyah.

[17] Prawirohardjo, S. (2010). Ilmu Kebidanan Edisi Keempat. Jakarta: Yayasan Bina Pustaka Sarwono Prawirohardjo.

[18] Purwakarta, D. K. (2014). Profil Kesehatan Pemerintahan Kab Purwakarta Tahun 2014. Purwakarta: Dinkes.

[19] Pusdiknakes. (2010). Konsep Asuhan Kebidanan. Jakarta: JHPIEGO.

[20] Ristica, O. D. (2013). Faktor Risiko Kejadian Anemia Pada Ibu Hamil 2013. Pekanbaru: Jurnal Kesehatan Komunitas Program Studi Kebidanan STIKES Hang Tuah .

[21] Rukiyah Ai Yeyeh, L. Y. (2010). Asuahan Kebidanan I Kehamilan Edisi Revisi. Jakarta Timur: CV. Tarns Info Media.

[22] Sarwono. (2010). IImu Kebidanan Edisi Keempat. Jakarta: Yayasan Bina Pustaka Sarwono Prawirohardjo.

[13] Subarda, M. H. (2011). Pelayanan Antenatal Care Dalam Pengelolaan Anemia Berhubungan Dengan Kepatuhan Ibu Hamil Minum Tablet Besi. Jakarta: Jurnal Gizi Klinik Indonesia.
[14] Syafrudin, Y. F. (2016). Promosi Kesehatan Untuk Mahasiswa Kebidanan . Jakarta: Trans Info Media.

[15] Tarwoto, W. (2007). Buku Saku Anemia Pada Kehamilan. Jakarta: Trans Info Media.

[16] Waryana. (2010). Gizin Reproduksi. Yogyakarta: Pustaka Rihana.

[17] Wiknjosasatro, H. (2002). Perubahan Anatomik dan Fisiologik Pada Wanita Hamil dalam IImu Kebidanan Edisi ke Tiga. Jakarta: Yayasan Bina Pustaka Sarwono Prawirohardjo .

[18] World Health Organization, G. (2012). Intermittent Iron And Folic Acid Supplementation In Non Anaemic Pregnant Women Geneve World Health Organization. Whorld Health Organization. 